\title{
Patient Safety in the Dialysis Facility
}

\author{
Alan S. Kliger \\ Yale University School of Medicine, and Department of Medicine, Hospital of St. Raphael, \\ New Haven, Conn., USA
}

\section{Key Words}

Patient and Quality Improvement Act · Root cause analyses - Dialyzer errors

\begin{abstract}
Medical mistakes that harm patients have occurred in dialysis facilities, just as they have been reported to cause death in hospitals. A plan to recognize and prevent mistakes includes several elements. (1) Establish a culture of safety, where safe practices are a priority and reporting of adverse events and 'near misses' is encouraged in a non-punitive environment. (2) Redesign processes of care to minimize patient falls, medication errors, bleeding from vascular accesses, dialyzer reuse errors and other problems. (3) Perform root cause analyses of adverse events and 'near misses'. (4) Involve patients in safety efforts, including maintaining an accurate, up-to-date medication list. (5) Dialysis facilities should function as high-reliability organizations, focusing on the possibility of failures, expecting to make errors, training to recognize and recover from them and making system reforms following root cause analyses.
\end{abstract}

Copyright @ 2006 S. Karger AG, Basel
On July 29, 2005, President Bush signed into law the Patient and Quality Improvement Act. This new law provides legal and confidentiality protection for safety information that health care providers share and creates patient safety organizations to promote information sharing [1]. This major step in the US brings us closer to creating a 'culture of safety' in our hospitals, outpatient clinics and dialysis facilities to reduce errors and adverse events. It comes several years after calls for regulatory protection from discovery for voluntary error and near-miss reporting systems [2]. Why is this legislation so vital, and how is it relevant to nephrologists, dialysis nurses, other professionals, administrators and dialysis facilities?

In 1999, the Institute of Medicine reported that as many as 98,000 Americans die each year in hospitals as a result of medical errors [3]. This remarkable estimate, extrapolated from two retrospective studies of in-hospital mortality, has been challenged by some and supported by others. Whatever the true number, it is clear that at a minimum, tens of thousands of Americans die each year not from their underlying disease, but rather as a result of errors in their care. Medical mistakes also occur in the outpatient setting. In 2002, the California Academy of Family Physicians reported that mistakes are common, often resulting from communication errors, discontinuity of care, failure to follow up on abnormal laboratory values, missing values, charting errors and prescribing errors [4]. A survey of large dialysis organizations conducted by

$\begin{array}{ll}\text { KARGER } & \text { ( 2006 S. Karger AG, Basel } \\ \text { Fax +4161306 1234 } 34-5068 / 06 / 0241-0000 \$ 23.50 / 0 \\ \begin{array}{l}\text { E-Mail karger@karger.ch } \\ \text { www.karger.com }\end{array} & \begin{array}{l}\text { Accessible online at: } \\ \text { www.karger.com/bpu }\end{array}\end{array}$

Alan S. Kliger, MD

Department of Medicine, Hospital of St. Raphael 1450 Chapel St.

New Haven, CT 06511 (USA)

Tel. +1 203789 3203, Fax +1 203789 3222, E-Mail AKliger@srhs.org 
the Renal Physicians Association, the Forum of EndStage Renal Disease Networks and the National Patient Safety Foundation identified several safety problems in dialysis facilities: patient falls, medication errors, vascular access-related events, dialyzer errors, excess blood loss and prolonged bleeding.

Several highly publicized cases of medical mistakes in dialysis and transplant patients underscore the need for the end-stage renal disease community to deal with this troubling problem. In one hemodialysis center, $10 \mathrm{Ser}$ ratia liquefaciens bloodstream infections and 6 pyrogenic reactions resulted from puncturing single-use vials of epoetin- $\alpha$ multiple times and pooling the preservativefree drug [5]. Root cause analysis showed multiple causes of this error, including human error, the practice of 'topping off' contaminated hand soap dispensers, pooling of multiple vials and a reimbursement system that forces maximal conservation of the drug [6]. In June 2004, hundreds of patients in British Columbia, Canada, were tested for hepatitis after several dialysis machines were found to have leaks, potentially exposing patients to the blood of others who had been dialyzed on that same machine. Finally, in February 2003, a teenager from Mexico died at Duke University after she mistakenly received a kidney transplant from a donor with a different blood type. Once again, a root cause analysis of this tragedy showed multiple breakdowns in the systems of care. On February 22, 2004, the New York Times quoted Peter Smith, MD, chief of Thoracic Surgery at Duke: 'It takes an event like this to raise the level of attention to the point where cultural change is possible.' The cultural change Dr. Smith referred to is the establishment of a culture of safety where safe practices are a priority and reporting of adverse events and 'near misses' is encouraged in a non-punitive environment to improve systems of care and reduce errors. Furthermore, physicians and medical centers can learn from the mistakes of others and can identify and adapt improved systems of care that others have devised. This is where the Patient and Quality Improvement Act facilitates a cultural change. In our highly litigious society, physicians and other providers are understandably reluctant to share any information about adverse events or 'near misses'. This law encourages voluntary reporting of errors, provides legal protection for those sharing such information for educational purposes, and creates a network of nation-wide patient safety organizations to facilitate such information sharing.

Many institutions and dialysis facilities have made progress in process redesign to improve patient safety. For example, a dialysis facility in Wheeling, W. Va., found that $40 \%$ of their patients had fallen at least once in a 6-month period, and $15 \%$ had multiple falls. Twentysix percent suffered injuries from these falls, $9 \%$ with fractured bones [7]. They now conduct fall risk assessments for all patients and provide focused education programs for patients, caregivers and staff to reduce falls. Physical therapists assist patients with physical strengthening exercises, and physicians are notified of falls at home so dialysis heparinization can be adjusted. In other institutions, preventable adverse drug events have been shown to decline when pharmacists participate on rounding teams in hospital general medicine units [8]. Dialysis patients often have several physicians, each of whom may prescribe different medications. The likelihood of adverse drug interactions, dosing errors with virtually absent renal function and hospital admissions and discharges when medications are altered, all make medication errors particularly possible. Practical tools to reduce medication errors during patient transfer [9] and a national call for patients to keep a list of all medications and share it with all prescribers have reduced medication errors. Another source of error is giving medicine or reprocessed dialyzers to the wrong patient. In March 2004, the Federal Drug Administration issued a rule requiring that certain human drug and biological product labels have bar codes. This bar coding is expected to help reduce the number of medication errors by allowing health care professionals to use bar code scanning equipment. Dialysis facilities can use bar-coded patient identification bracelets or identity cards to confirm correct administration of medications, reused dialyzers and other procedures.

Improving patient safety requires commitment from all. Providers must be encouraged to report errors and 'near misses' in a non-punitive environment and such reports should serve to examine and improve systems of care. Facility administrators should champion root cause analyses of adverse events and 'near misses', refrain from blaming those involved and support process redesign when appropriate. Patient safety organizations should facilitate sharing of patient safety information and best practices. Patients should play an integral role in patient safety, be responsible for maintaining an accurate updated medication list and sharing their perception of patient safety and opportunities for improvement with facility providers and administrators. As 'high reliability organizations', dialysis facilities should keep focused on the possibility of failure, expect to make errors and train to recognize and recover from them, learn from failures by generalizing instead of isolating them and look for system reform rather than make local repairs. 


\section{References}

1 AHA News Now, Patient safety bill becomes law. July 29, 2005. www.AHANews.com.

$\checkmark 2$ Kliger AS, Diamond LH: Patient safety in endstage renal disease: how do we create a safe environment? Adv Ren Replace Ther 2001;8: 131-137.

3 Kohn LT, Corrigan JM, Donaldson MS (eds): To Err Is Human: Building a Safer Health Care System. Washington, National Academy Press, 2000 .
4 California Academy of Family Physicians: Diagnosing and treating medical errors in family practice. www.familydocs.org/monographs. php.

5 Grohskopf LA, Roth VR, Feikin DR, et al: Serratia liquefaciens blood-stream infections from contamination of epotin alfa at a hemodialysis center. N Engl J Med 2001;344:1491-1497.

6 DeOreo PB, Kliger AS: Serratia liquefaciens infections at a hemodialysis center. N Engl J Med 2001;345:921.

7 Latos DL, Postlethwait H, Haley R: Falls among chronic hemodialysis patients: a major safety issue (abstract). J Am Soc Nephrol 2002; 13:SA-PO657.
8 Kucukarslan SN, Peters M, Mlynarek M, Nafziger DA: Pharmacists on rounding teams reduce preventable adverse drug events in hospital general medicine units. Arch Intern Med 2003; 163:2014-2018.

9 Pronovost PP, Baugher Hobson D, Earsing K, Lins ES, et al: A practical tool to reduce medication errors during patient transfer from an intensive care unit. J Clin Outcomes Manage 2004; 11:26-33. 